\title{
Hispidulin modulates epithelial-mesenchymal transition in breast cancer cells
}

\author{
HYUN A. KIM and JOOMIN LEE \\ Department of Food and Nutrition, Chosun University, Gwangju 61452, Republic of Korea
}

Received September 23, 2020; Accepted December 14, 2020

DOI: 10.3892/ol.2020.12416

\begin{abstract}
Breast cancer is the most commonly diagnosed cancer worldwide. Despite the use of chemotherapeutic drugs, drug resistance has been observed in numerous patients with breast cancer. Epithelial-mesenchymal transition (EMT) is an important initiation step in the process of metastasis, whereby cancer cells move away from the original tumor site. Therefore, the discovery of new substances that suppress EMT is a promising avenue for cancer treatment. The present study investigated the effect of hispidulin, a polyphenolic flavonoid, on EMT in human breast cancer cells in vitro (MCF-7 and HCC38). The EMT-associated mRNA and protein expression levels were measured using reverse transcription-quantitative PCR or western blot analysis. Hispidulin treatment increased the expression levels of EMT-associated epithelial markers and decreased the expression levels of mesenchymal markers in both cells. Transforming growth factor- $\beta 1$ (TGF- $\beta 1$ ) treatment increased breast cancer cell viability (assessed via MTS assay) and EMT induction. However, hispidulin and TGF- $\beta 1$ co-treatment increased the expression levels of E-cadherin and occludin, while downregulating vimentin expression. Additionally, hispidulin treatment inhibited TGF- $\beta 1$-induced Smad2/3 signaling and cell migration in both breast cancer cell lines. Overall, the current findings suggested that hispidulin may inhibit EMT and cell migration by suppressing the Smad2/3 signaling pathway in breast cancer cells.
\end{abstract}

\section{Introduction}

Breast cancer is the leading cause of cancer-related deaths in women worldwide (1). Breast cancer risk is increased by prolonged estrogen exposure, such as early menarche, late

Correspondence to: Professor Joomin Lee, Department of Food and Nutrition, Chosun University, 309 Pilmun-daero, Dong-gu, Gwangju 61452, Republic of Korea

E-mail: joominlee@chosun.ac.kr

Key words: hispidulin, epithelial-mesenchymal transition, transforming growth factor- $\beta 1$, migration, breast cancer menopause, having no childbirth experience, or increased estrogen levels in adipocytes due to obesity $(2,3)$. In addition, mutated BRCA1 and BRCA2 genes are associated with breast cancer risk (4). Management strategies for breast cancer include surgery, radiotherapy, chemotherapy, endocrine treatment, and targeted treatment (5). Among these treatments, anticancer drugs have been widely used for breast cancer treatment. For example, tamoxifen acts on the estrogen pathway and is applied in estrogen receptor-positive breast cancer patients (6). Patients who have high levels of metastatic human epidermal growth factor receptor 2 (HER2)/neu are prescribed trastuzumab, which blocks the HER2 signal and improves patient outcomes (7). However, these chemotherapy drugs have side effects including early menopause, depression, rash, and renal toxicity.

Epithelial-mesenchymal transition (EMT) is a process associated with the disruption of cell junctions and the loss of cell polarity, which increases cell mobility and allows them to acquire stem cell-like properties (8). As its name suggests, EMT causes the loss of epithelial markers (E-cadherin and occludin) and acquisition of mesenchymal markers (fibronectin, vimentin and N-cadherin) (9). EMT is induced by numerous growth factors and related signaling pathways, including transforming growth factor- $\beta 1$ (TGF- $\beta 1$ ) (10). TGF- $\beta 1$ plays a prominent role in breast cancer progression and bone metastasis (11).

Hispidulin (4',5,7-trihydroxyl-6-methoxyflavone) is a phenolic flavonoid compound widely used in traditional medicine (12). Several studies have shown that hispidulin has anti-obesity, antioxidant, anti-mutagenic, anti-inflammatory, and anti-tumor effects (13-17). Hispidulin also has anticonvulsant, neuroprotective, and anti-osteoporosis effects (18-21). However, the role of hispidulin in EMT has not yet been studied in breast cancer. In this study, we used two breast cancer cell lines, luminal type cells (MCF-7) with strong cell-to-cell adhesion and an aggregated structure, and claudin-low type cells (HCC38) with an invasive form and high metastatic properties due to weak cohesion between cells. We aimed to investigate the effect of hispidulin on EMT and cell migration induced by TGF- $\beta 1$ treatment in breast cancer cells.

\section{Materials and methods}

Reagents and antibodies. Hispidulin was purchased from Sigma-Aldrich; Merck KGaA and was dissolved in dimethyl sulf- 
A<smiles>COc1c(O)cc2oc(-c3ccc(O)cc3)cc(=O)c2c1O</smiles>

B

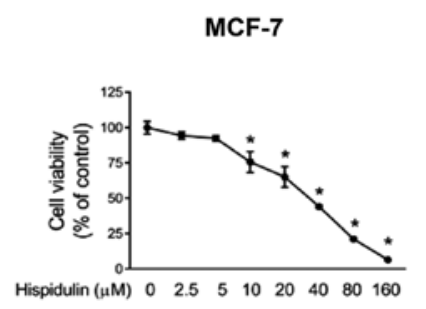

MCF-7

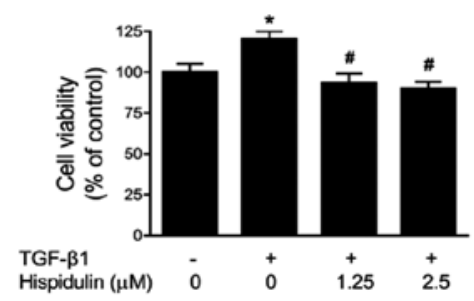

HCC38

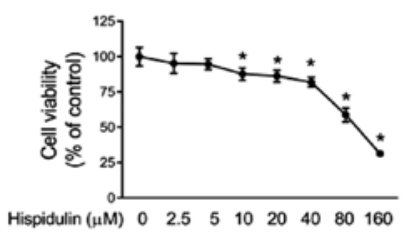

HCC38

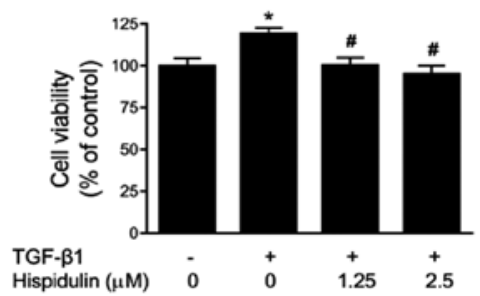

Figure 1. Effect of hispidulin on the viability of breast cancer cells. (A) Structure of hispidulin. (B) Breast cancer cells were treated with hispidulin and/or TGF- $\beta 1$ and assessed using an MTS assay. Data are expressed as the mean \pm SD of at least three independent experiments. "P<0.05 vs. DMSO-control group; ${ }^{\text {" }} \mathrm{P}<0.05$ vs. TGF- $\beta 1$-treated group. TGF- $\beta 1$, transforming growth factor- $\beta 1$.

oxide(DMSO) and mixed with fresh medium to achieve the desired final concentrations. TGF- $\beta 1$ was purchased from R\&D Systems. The following primary antibodies were used in the experiment: anti- $\beta$-actin and anti-total-Smad2/3 (Santa Cruz Biotechnology, Inc.), anti-phospho-Smad2/3 (Cell Signaling Technology, Inc.), anti-vimentin (Sigma-Aldrich; Merck KGaA), anti-E-cadherin, and anti-occludin (BD Biosciences). The secondary antibodies used were horseradish peroxidase (HRP-conjugated anti-mouse; Santa Cruz Biotechnology, Inc.) and HRP-conjugated anti-rabbit (Cell Signaling Technology, Inc.).

Cell culture. The two breast cancer cell lines used in this study (MCF-7 and HCC38) were obtained from the Korean Cell Line Bank (Seoul, Korea) and cultured in RPMI-1640 medium (Gibco; Thermo Fisher Scientific, Inc.) containing $1 \%$ penicillin, streptomycin, and $10 \%$ fetal bovine serum (FBS; Gibco; Thermo Fisher Scientific, Inc.) at $37^{\circ} \mathrm{C}$ in a $5 \% \mathrm{CO}_{2}$ atmosphere.

Cell viability assay. Breast cancer cell viability was assessed using the 3-(4,5-Dimethylthiazol-2-yl)5-(3-carboxymethoxyphenyl)-2-(4-sulfophenyl)-2H-tetrazolium (MTS) assay, as previously described (22). Briefly, cells were plated $\left(2 \times 10^{3}\right.$ cells/well) in 96-well plates and allowed to grow overnight. Cells were treated with various concentrations of hispidulin and/or TGF- $\beta 1$ for $24 \mathrm{~h}$. Next, MTS reagent was added to each well according to the manufacturer's protocol.
RNA isolation and reverse transcription-quantitative polymerase chain reaction. Total RNA was extracted from hispidulin-treated breast cancer cells using the RNeasy mini kit (Qiagen) and cDNA was obtained using AccuPower ${ }^{\circledR}$ RT PreMix (Bioneer). Quantitative PCR was performed as described previously (22). All experiments were performed in triplicate. The relative change of each gene was normalized to the expression of glyceraldehyde-3-phosphate dehydrogenase (GAPDH). The fold-changes in mRNA expression were calculated using the $2^{-\triangle \Delta C q}$ method (23). The primers were as follows: E-cadherin, forward 5'-AAAGGCCCATTTCCTAAAAAC CT-3' and reverse 5'-TGCGTTCTCTATCCAGAGGCT-3'; occludin, forward 5'-CTTCAGGCAGCCTCGTTACA-3' and reverse 5'-TACCTGATCCAGTCCTCCTC-3; vimentin, forward 5'-CTCTTCCAAACTTTTCCTCCC-3'; and reverse 5'-AGTTTCGTTGATAACCTGTCC-3'; GAPDH, forward 5'-GGACCTGACCTGCCGTCTAGAA-3' and reverse 5'-GGT GTCGCTGTTGAAGTCAGAG-3'.

Western blot. After treatment with hispidulin and/or TGF- $\beta 1$ for $24 \mathrm{~h}$, cell lysates were collected and prepared. Protein concentration was quantified using the Bradford assay (BioRad Laboratories, Inc.). After SDS-PAGE, the proteins were transferred onto polyvinylidene difluoride (PVDF) membranes (EMD Millipore). After blocking with 5\% non-fat dry milk, the membranes were probed with different primary antibodies. Membranes were incubated with an HRP-conjugated 

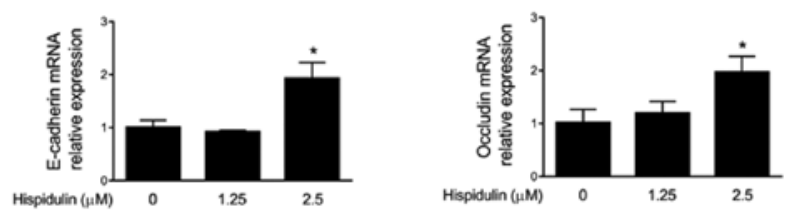

HCC38

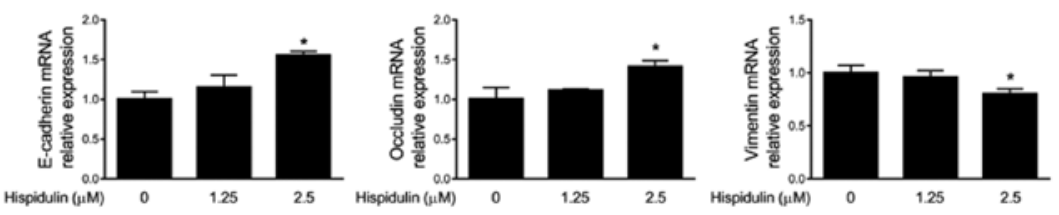

B

MCF-7

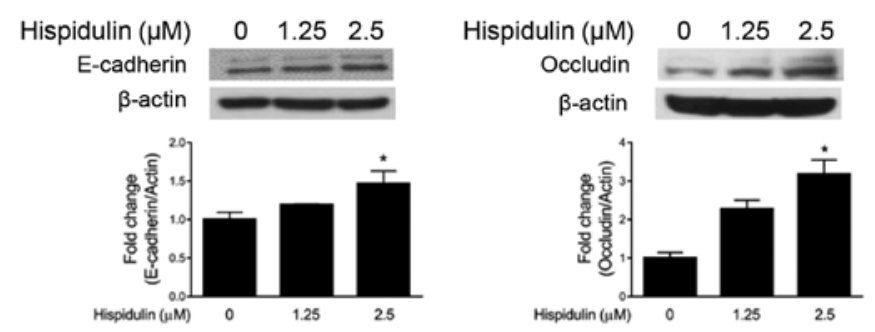

HCC38

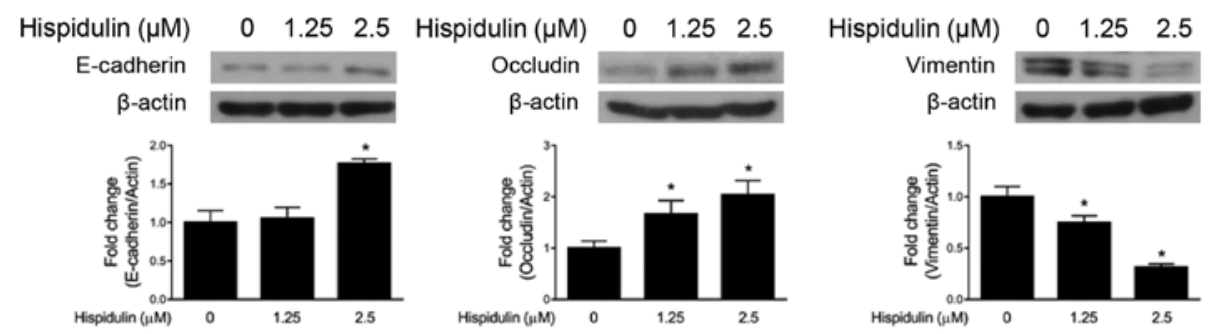

Figure 2. Effect of hispidulin on EMT markers in MCF-7 and HCC38 cells. Breast cancer cells were treated with hispidulin for $24 \mathrm{~h}$ and EMT markers were evaluated by (A) reverse transcription-quantitative PCR and (B) western blot analysis. Data are expressed as the mean \pm SD of at least three independent experiments. ${ }^{*}<0.05$ vs. DMSO-control group. EMT, epithelial-mesenchymal transition.

secondary antibody for $1 \mathrm{~h}$, and protein detection was performed using enhanced chemiluminescence (ECL) solution (PerkinElmer).

Confocal microscopy. Fluorescent images were examined as previously described (22). Briefly, the treated breast cancer cells were fixed in $4 \%$ paraformaldehyde for $1 \mathrm{~h}$. Then, the cells were permeabilized with $0.5 \%$ Triton X-100, blocked in $1 \%$ bovine serum albumin (BSA), and stained with the primary antibody overnight at $4^{\circ} \mathrm{C}$. Cells were treated with secondary antibody for $1 \mathrm{~h}$ and then mounted using 4',6-diamidino-2-phenylindole (DAPI). Cells were observed using confocal microscopy (LSM-700; Carl Zeiss).

Wound healing assay. Each breast cancer cell line $\left(4 \times 10^{5}\right.$ cells) was seeded in a 12 -well plate and allowed to grow until approximately $90 \%$ confluence. Then, the media was removed and the monolayer was scratched with a pipette tip. $10 \mathrm{ng} / \mathrm{ml} \mathrm{TGF}-\beta 1$ and hispidulin $(1.25$ and $2.5 \mu \mathrm{M})$-treated cells were maintained in $1 \%$ FBS-containing media for $24 \mathrm{~h}$.
The media was then removed and the cells were washed with phosphate-buffered saline (PBS). After fixing with methanol, the cells were stained with Giemsa stain solution (Sigma-Aldrich; Merck KGaA) for $1 \mathrm{~h}$. Cells were then observed and photographed using an optical microscope (CKX41; Olympus Corporation) and analyzed using Image J software (NIH).

Transwell migration assay. Breast cancer cells were plated in the upper chamber of transwell plates containing TGF- $\beta 1$ $(10 \mathrm{ng} / \mathrm{ml})$ and hispidulin $(1.25$ and $2.5 \mu \mathrm{M})$ (Costar). The lower chamber was supplemented with serum-free media containing 5\% FBS. After $24 \mathrm{~h}$ of incubation, the cells were fixed with methanol. Cells were stained with hematoxylin (Sigma-Aldrich; Merck KGaA) and eosin (Sigma-Aldrich; Merck KGaA). Cells were then photographed using an optical microscope (CKX41; Olympus Corporation).

Statistical analysis. Graph Pad Prism 6 Software (GraphPad Software, Inc.) was used for statistical analysis. All experiments 

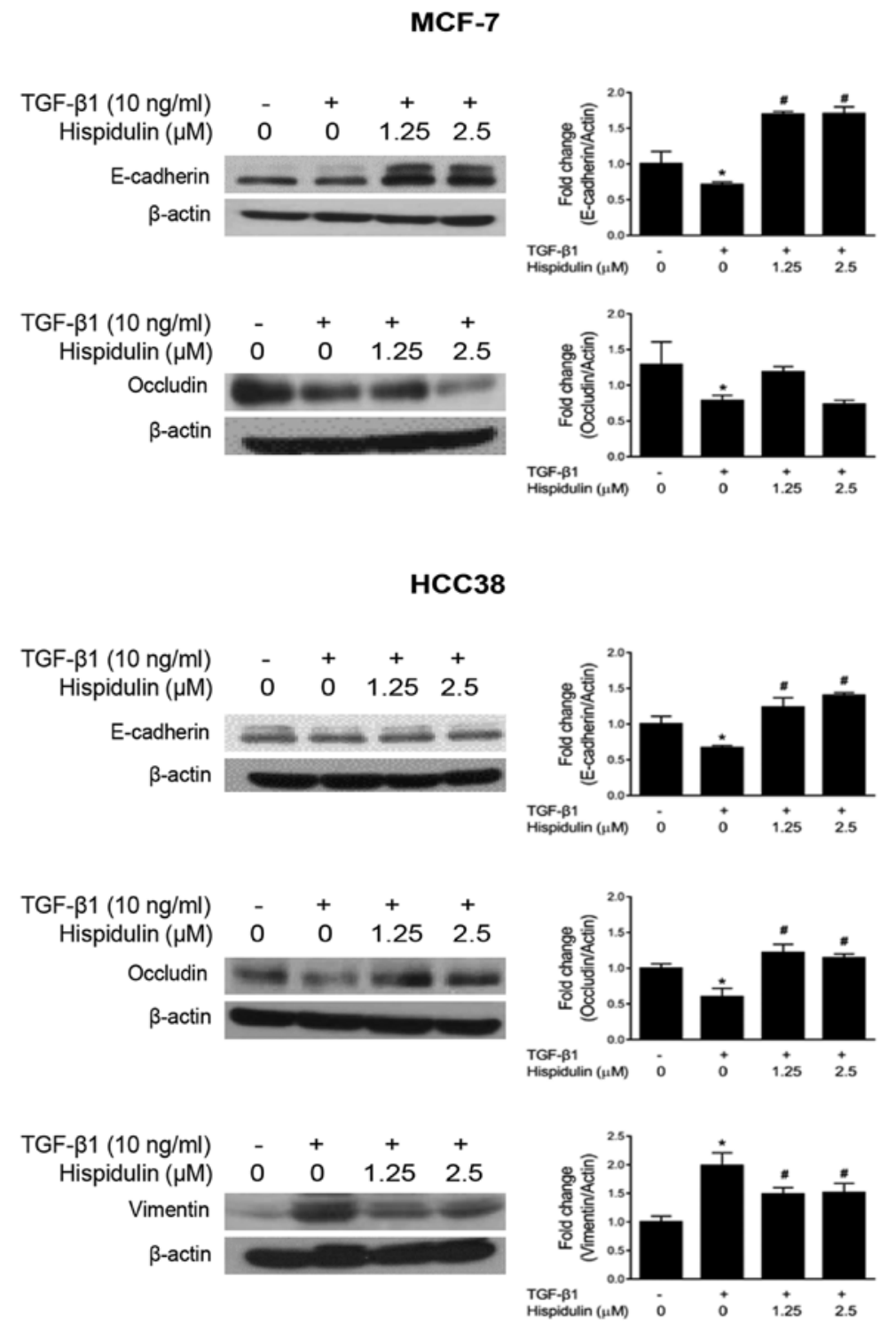

Figure 3. Hispidulin regulation on TGF- $\beta 1$-induced EMT markers in breast cancer cells. MCF-7 and HCC 38 cells were treated with hispidulin and TGF- $\beta 1$ for $24 \mathrm{~h}$. EMT markers (E-cadherin, occludin and vimentin) were detected by western blot assay. Data are expressed as the mean \pm SD of at least three independent experiments. ${ }^{*} \mathrm{P}<0.05$ vs. DMSO-control group; ${ }^{*} \mathrm{P}<0.05$ vs. TGF- $\beta 1$-treated group. TGF- $\beta 1$, transforming growth factor- $\beta 1$; EMT, epithelial-mesenchymal transition.

were performed three times, independently. One-way ANOVA with Bonferroni post-hoc test was used for statistical analysis of the data. $\mathrm{P}<0.05$ was considered to indicate a statistically significant difference.

\section{Results}

Hispidulin inhibits breast cancer cell viability. The chemical structure of hispidulin is shown in Fig. 1A. We first determined the inhibitory effect of hispidulin on the viability of breast cancer cells. MCF-7 and HCC 38 cancer cells were treated with various concentrations of hispidulin for $24 \mathrm{~h}$. We observed that the $50 \%$ inhibitory concentration $\left(\mathrm{IC}_{50}\right)$ values of hispidulin in MCF-7 and HCC38 cells were $25.44 \pm 0.23$ and $65.42 \pm 0.31 \mu \mathrm{M}$, respectively. The inhibition rate of hispidulin in MCF-7 and HCC38 breast cell lines increased with increasing concentration. Next, we determined the TGF- $\beta 1$-induced inhibitory effect of hispidulin on cell viability. As shown in Fig. 1B,
MCF-7 and HCC38 cells showed a significant increase in growth after treatment with only TGF- $\beta 1$ compared to treatment with DMSO control for $24 \mathrm{~h}$. However, treatment with both TGF- $\beta 1$ and hispidulin caused a significant growth reduction compared to the TGF- $\beta 1$-treated group in both cell lines.

Hispidulin treatment increases the expression of epithelial markers in breast cancer cells. We studied the effect of hispidulin on EMT markers in MCF-7 and HCC38 cells. Interestingly, $2.5 \mu \mathrm{M}$ of hispidulin significantly increased the mRNA expression of epithelial markers such as E-cadherin and occludin in MCF-7 and HCC38 cells (Fig. 2A). Moreover, hispidulin decreased the expression of vimentin mRNA in HCC38 cells. As shown in Fig. 2B, hispidulin increased the protein expression of E-cadherin and occludin in MCF-7 cells, and similar results were obtained in HCC38 cells. Vimentin protein expression was significantly decreased after hispidulin treatment in HCC38 cells. 

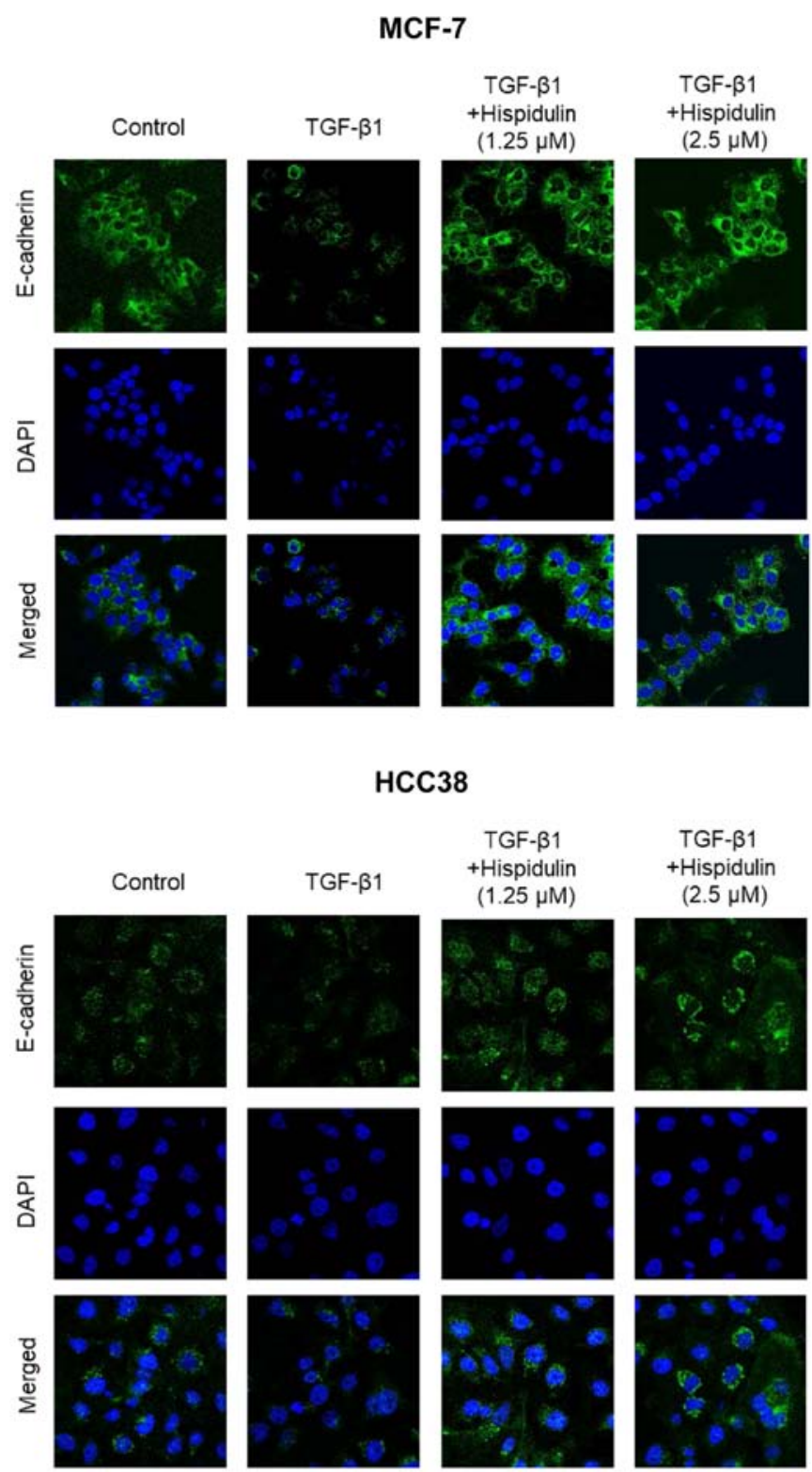

Figure 4. Effect of hispidulin on TGF- $\beta 1$-induced E-cadherin expression by immunofluorescence analysis in breast cancer cells. MCF-7 and HCC38 cells were treated with hispidulin in the presence of TGF- $\beta 1$ for $24 \mathrm{~h}$. Cells were stained with an antibody against E-cadherin and DAPI. Magnification, x40. TGF- $\beta 1$, transforming growth factor- $\beta 1$.

Hispidulin suppresses EMT through TGF- $\beta 1$ in breast cancer cells. TGF- $\beta 1$ plays a key role in maintaining the balance between cell differentiation and regeneration in normal epithelial cells (24). However, TGF- $\beta 1$ promotes EMT, invasion, and immunosuppression in advanced cancers (25). We investigated the effect of hispidulin treatment on TGF- 31 -induced EMT in breast cancer cells. As shown in Fig. 3, both breast cancer cells treated with both TGF- $\beta 1$ and hispidulin had increased protein expression of E-cadherin compared to the cells treated with TGF- $\beta 1$ alone. After TGF- $\beta 1$ and hispidulin co-treatment, the expression of occludin increased compared to TGF- $\beta 1$ treatment alone in HCC38 cells. Occludin protein expression was assessed in MCF-7 cells, but no significant changes were found among the treatment groups (Fig. 3). TGF- $\beta 1$ and hispidulin co-treatment decreased vimentin protein expression in HCC 38 cells. To confirm these results, immunofluorescence was performed. As shown in Fig. 4, TGF- $\beta 1$ and hispidulin co-treatment increased the expression of E-cadherin compared to TGF- $\beta 1$ treatment alone in both MCF-7 and HCC38 cells. These data suggest that hispidulin inhibits TGF- $\beta 1$-induced EMT.

Hispidulin downregulates TGF- $\beta 1$-induced Smad signaling. TGF- $\beta 1$ induces EMT via Smad signaling pathways $(26,27)$. TGF- $\beta$ signaling is initiated upon the interaction of TGF- $\beta 1$ with transmembrane kinase receptors, causing the activation of downstream signaling pathways involving Smad2 and/or 3 (Smad2/3) and Smad4. Our data showed that phospho-Smad2/3 protein expression was significantly increased after TGF- $\beta 1$ treatment compared to the DMSO (control) treatment, but the protein expression of total Smad2/3 did not change in either cancer cell line (Fig. 5). However, TGF- $\beta 1$ and hispidulin co-treatment significantly inhibited the phosphorylation of Smad2/3 protein in breast cancer cells. 

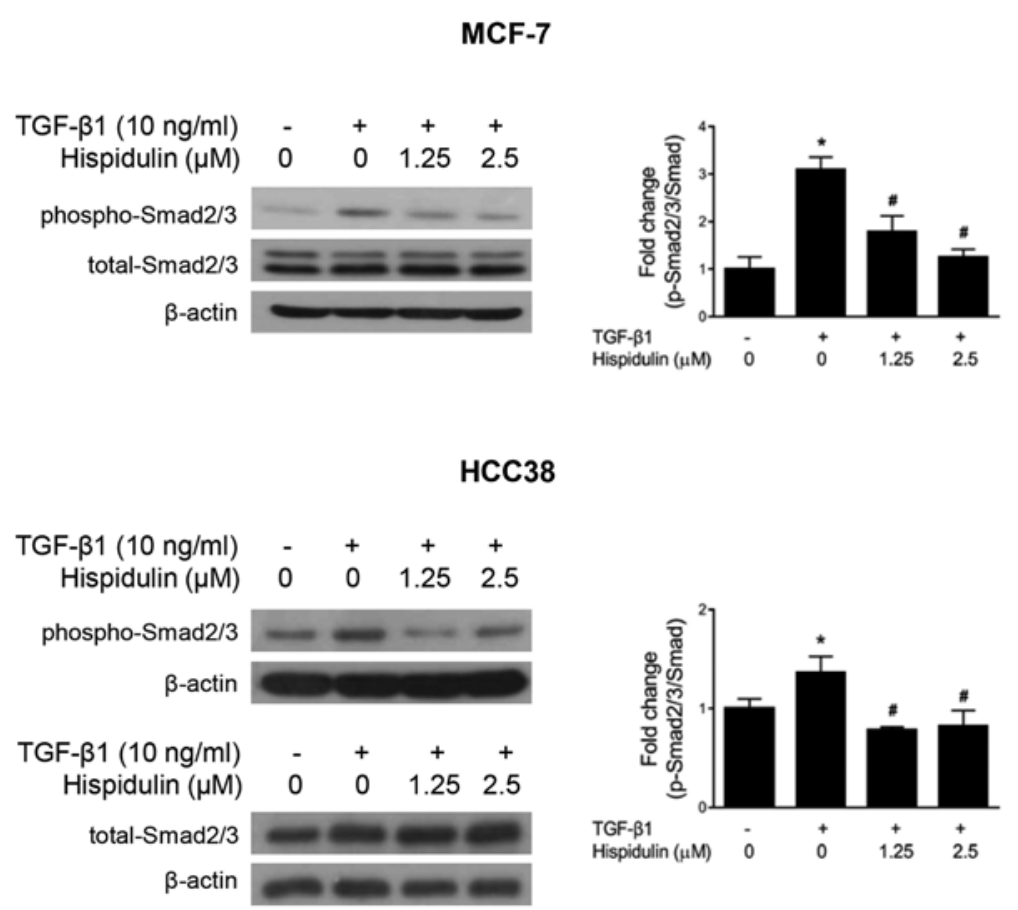

Figure 5. Effect of hispidulin on TGF- $\beta 1$-induced Smad signaling in MCF-7 and HCC38 cells. The protein expression levels of phospho-Smad and total Smad were analyzed using western blot analysis. Data are expressed as the mean $\pm \mathrm{SD}$ of at least three independent experiments. " $\mathrm{P}<0.05$ vs. DMSO-control group; ${ }^{\#} \mathrm{P}<0.05$ vs. TGF- $\beta 1$-treated group. TGF- $\beta 1$, transforming growth factor- $\beta 1$.

Hispidulin inhibits TGF- $\beta 1$-induced cell migration in breast cancer cells. To assess whether hispidulin influences cell migration, we performed migration assays in breast cancer cells. The wound area in cells treated with TGF- $\beta 1$ was significantly reduced compared to that in cells treated with DMSO (control) (Fig. 6A). After TGF- $\beta 1$ and hispidulin co-treatment, the wound area was significantly increased compared to that in the TGF- $\beta 1$ treatment group. In addition, the percentage of cell migration in cells treated with TGF- $\beta 1$ and hispidulin was significantly suppressed compared to the TGF- $\beta 1$ treatment according to the Transwell assay in both breast cancer cell lines (Fig. 6B).

\section{Discussion}

Recent studies have shown that bioactive compounds in natural products have anticancer activities, and these substances can be effective in preventing and treating cancer (28). The natural compound hispidulin is a phenolic flavonoid found in Lamiaceae plants and has shown various effects against cancers (29-33). However, studies on the effect of hispidulin on EMT in breast cancer are limited. In this study, we studied the effect of hispidulin on two breast cancer cell lines: MCF-7 of the luminal A type [estrogen receptor $(\mathrm{ER})^{+}$, progesterone receptor $(\mathrm{PR})^{+/}$, human epidermal growth factor receptor 2 (HER2)-], and HCC38 of the claudin-low type (ER-, PR', HER2') (34). Our results, for the first time, demonstrated that hispidulin inhibits EMT and cell migration through E-cadherin-mediated reorganization after TGF- $\beta 1$ treatment in breast cancer cells.

EMT is an essential process in the early stages of embryonic development, but uncontrolled EMT is associated with tumorigenesis (35). During EMT, cancer cells lose the properties of epithelial cells and acquire the properties of mesenchymal cells, allowing them to migrate to other organs through blood vessels or lymph nodes, causing metastasis and recurrence (36). Most cancer-related deaths are due to metastasis, which includes cell discharge from the primary tumor to the circulatory system, survival in the circulatory system, adaptation in new organs, initiation and maintenance of growth, and angiogenesis of metastasized tumors $(7,9,37)$. Low expression of E-cadherin plays an important role in cancer metastasis and is associated with a reduced survival rate in breast cancer patients $(38,39)$. Occludin is an integral membrane protein located in tight junctions that physically creates a barrier between cells (40). Loss of occludin affects bone metastasis in cancer patients (41). It has been shown that vimentin, a type III intermediate fibrous protein, is extensively expressed in triple-negative breast cancer subtypes and is correlated with tumor invasiveness and resistance to chemotherapy $(42,43)$. In our study, hispidulin treatment increased the expression of E-cadherin and occludin and downregulated vimentin, with or without TGF- $\beta 1$ treatment (Fig. 5). These results showed that hispidulin modulated EMT in breast cancers.

TGF- $\beta 1$ acts as a tumor suppressor in normal epithelial cells, but promotes tumorigenesis, metastasis, cancer stem cell formation, and immune suppression in cancer cells (44). High levels of TGF- $\beta 1$ are found in triple-negative breast carcinomas and are associated with metastasis and tumor progression $(24,45,46)$. TGF- $\beta 1$ also stimulates metastatic progression, leading to the development of chemoresistance in breast cancer stem cells (47). Moreover, TGF- $\beta 1$ can induce EMT and increase cell motility (48). Our study revealed that TGF- $\beta 1$ decreased the expression of E-cadherin and occludin proteins and increased the expression of vimentin in breast cancer cells (Fig. 5). However, hispidulin reversed the TGF- $\beta 1$-induced EMT phenomenon. Therefore, hispidulin may be effective in inhibiting TGF- $\beta 1$-induced EMT in breast cancer cells. 
A

MCF-7
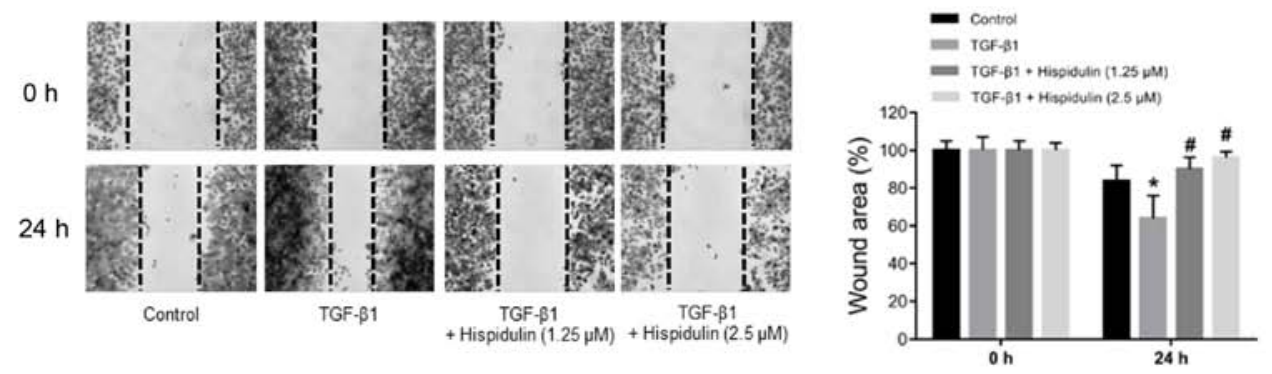

HCC38
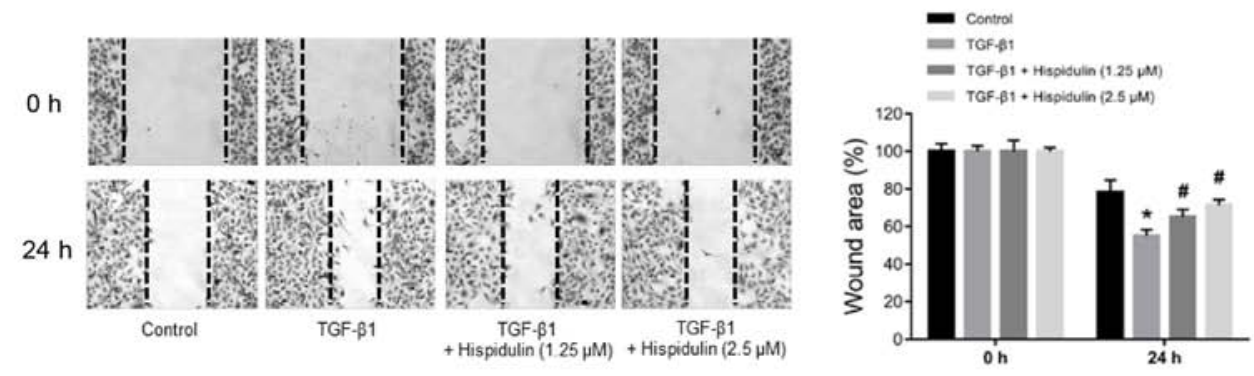

B

\section{MCF-7}
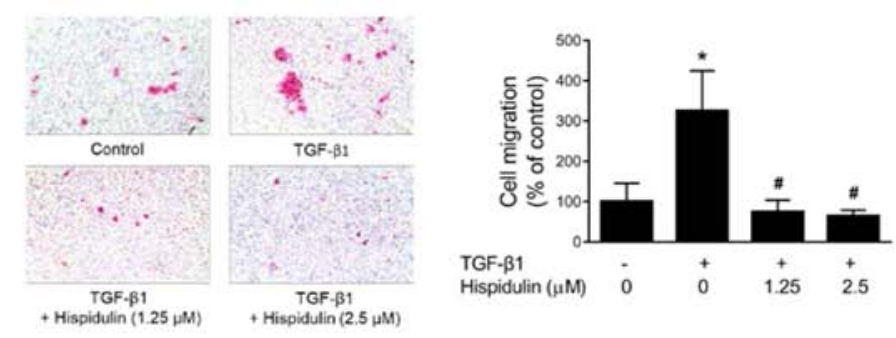

HCC38
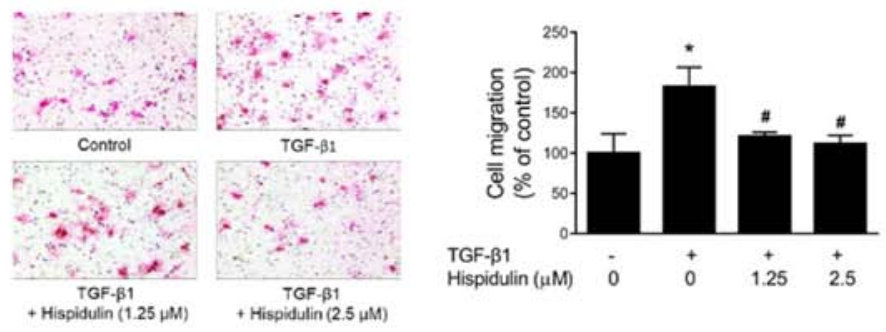

Figure 6. Hispidulin inhibited TGF- $\beta 1$-induced breast cancer cell migration. (A) Wound healing assay in MCF-7 and HCC38 cells. Confluent monolayers of MCF-7 and HCC 38 cells were treated with hispidulin and TGF- $\beta 1$ for 0 and $24 \mathrm{~h}$. Quantification of the scratched area was performed using ImageJ software. (B) Transwell assay in MCF-7 and HCC38 cells. Cells treated with hispidulin $(1.25$ or $2.5 \mu \mathrm{M})$ and TGF- $\beta 1(10 \mathrm{ng} / \mathrm{ml})$ were seeded into the Transwell upper chamber. The lower chamber was filled with 5\% FBS-containing media. Following a $24 \mathrm{~h}$ incubation, migrated cells were stained with hematoxylin and eosin. Data are expressed as the mean $\pm \mathrm{SD}$ of at least three independent experiments. Magnification, $\mathrm{x} 10 .{ }^{*} \mathrm{P}<0.05$ vs. DMSO-control group; ${ }^{\prime} \mathrm{P}<0.05$ vs. TGF- $\beta 1$-treated group. TGF- $\beta 1$, transforming growth factor- $\beta 1$.

TGF- $\beta 1$ induces EMT via the activation of Smad-dependent and Smad-independent signaling (46). TGF- $\beta 1$ binds to TGF- $\beta 1$ type II receptors (T $\beta R I I)$ and TGF- $\beta 1$ type I receptors (T $\beta R I)$ at serine and threonine residues. $\operatorname{Smad} 2 / 3$ is then phosphorylated and activates the expression of EMT-related transcription factors (49-52). Our data demonstrates that hispidulin inhibits the expression of phosphorylated-Smad $2 / 3$ induced by TGF- $\beta 1$ in MCF-7 and HCC38 cell lines (Fig. 5). Some clinical studies have shown that TGF- $\beta 1$-targeting anticancer compounds have therapeutic effects in breast cancer patients (53). Thus, we suggest that hispidulin may be a chemo-therapeutic via targeting TGF- $\beta 1$ signaling in breast cancers. However, further experiments are needed to investigate non-Smad signaling in breast cancers.

Loosely connected mesenchymal cells developed through EMT can migrate and invade other tissues (54). The present study demonstrated that the motility of cells increases after TGF- $\beta 1$ treatment; however, TGF- $\beta 1$ and hispidulin co-treatment decreases cell migration in MCF-7 and HCC38 cells, as assessed through wound healing and Transwell migration assays (Fig. 5). EMT stimulates tumor cells to acquire stem 
cell-like properties and increases their resistance to standard chemotherapeutic drugs as well as conventional chemotherapy and radiotherapy $(55,56)$. Our study demonstrated that the inhibitory effects of hispidulin on EMT can be modulated against both MCF-7 (moderately invasive) and HCC38 (highly invasive) breast cancers. Most studies using hispidulin have focused on anti-cancer effects, including apoptosis signaling including mitochondrial ROS, cell cycle mediated apoptosis using various cancer cells (57). However, the role of hispidulin in TGF- $\beta 1$-induced EMT in human breast cells has not been elucidated. The concentration of hispidulin used in other cancer studies was over $10 \mu \mathrm{M}$ (58). Our study showed that hispidulin was effective at concentrations below $5 \mu \mathrm{M}$ for EMT inhibition. Therefore, this is the first study to show that the suppression of EMT using hispidulin is a strategy for preventing and treating breast cancers. Furthermore, several studies have shown that hispidulin, in various drug combinations, has synergistic effects against cancers (59). Hispidulin enhances the anticancer effect of chemotherapeutic drugs including gemcitabine, 5-fluorouracil, mitoxantrone, sunitinib, temozolomide, and tumor necrosis factor-related apoptosis-inducing ligand (TRAIL) (17,30,59-62).

However, there is a need for more research on the synergistic effects of hispidulin and breast cancer drugs. We found that hispidulin is rapidly absorbed in the stomach and intestines, with an absolute bioavailability of $4.02 \%$ after oral administration (63). Therefore, hispidulin requires additional strategies to enhance its efficacy for practical clinical use in chemoprevention and chemotherapy.

In conclusion, we show that hispidulin can block EMT and that this effect may be associated with a decrease in TGF- $\beta 1$-induced signaling. Additionally, hispidulin inhibited breast cancer cell migration after TGF- $\beta 1$ treatment. Thus, hispidulin may represent a novel anticancer agent for the treatment of early and late stage breast cancers.

\section{Acknowledgements}

Not applicable.

\section{Funding}

The present study was supported by a research fund from Chosun University (2020).

\section{Availability of data and materials}

The datasets used and/or analyzed during the current study are available from the corresponding author on reasonable request.

\section{Authors' contributions}

JL conceived and designed the study. HAK performed the experiments. JL and HAK analyzed the data and wrote the manuscript. JL and HAK confirm the authenticity of all the raw data. All authors read and approved the final manuscript and agreed to be accountable for all aspects of the research.

\section{Ethics approval and consent to participate}

Not applicable.

\section{Patient consent for publication}

Not applicable.

\section{Competing interests}

The authors declare that they have no competing interests.

\section{References}

1. Torre LA, Islami F, Siegel RL, Ward EM and Jemal A: Global Cancer in Women: Burden and Trends. Cancer Epidemiol Biomarkers Prev 26: 444-457, 2017.

2. Yoo KY, Kang D, Park SK, Kim SU, Kim SU, Shin A, Yoon H, Ahn SH, Noh DY and Choe KJ: Epidemiology of breast cancer in Korea: Occurrence, high-risk groups, and prevention. J Korean Med Sci 17: 1-6, 2002.

3. Park B, Park S, Shin HR, Shin A, Yeo Y, Choi JY, Jung KW, Kim BG, Kim YM, Noh DY, et al: Erratum to: Population attributable risks of modifiable reproductive factors for breast and ovarian cancers in Korea. BMC Cancer 16: 181, 2016. Erratum for: BMC Cancer 16: 5, 2016.

4. Irving M, Elmslie F and Berg J: 18. Genetics of breast cancer. Int J Clin Pract 56: 677-682, 2002

5. Radice D and Redaelli A: Breast cancer management: Quality-of-life and cost considerations. Pharmacoeconomics 21: 383-396, 2003.

6. Osborne CK: Tamoxifen in the treatment of breast cancer. N Engl J Med 339: 1609-1618, 1998.

7. Zeeshan R and Mutahir Z: Cancer metastasis - tricks of the trade. Bosn J Basic Med Sci 17: 172-182, 2017.

8. Liao TT and Yang MH: Revisiting epithelial-mesenchymal transition in cancer metastasis: The connection between epithelial plasticity and stemness. Mol Oncol 11: 792-804, 2017.

9. Yeung KT and Yang J: Epithelial-mesenchymal transition in tumor metastasis. Mol Oncol 11: 28-39, 2017.

10. Gloushankova NA, Zhitnyak IY and Rubtsova SN: Role of epithelial-mesenchymal transition in tumor progression. Biochemistry (Mosc) 83: 1469-1476, 2018.

11. Yu H, Shen Y, Hong J, Xia Q, Zhou F and Liu X: The contribution of TGF- $\beta$ in Epithelial-Mesenchymal Transition (EMT): Down-regulation of E-cadherin via snail. Neoplasma 62: 1-15, 2015.

12. Patel K and Patel DK: Medicinal importance, pharmacological activities, and analytical aspects of hispidulin: A concise report. J Tradit Complement Med 7: 360-366, 2016.

13. Lee SG, Kim JS, Min K, Kwon TK and Nam JO: Hispidulin inhibits adipogenesis in 3T3-L1 adipocytes through PPAR $\gamma$ pathway. Chem Biol Interact 293: 89-93, 2018.

14. Dabaghi-Barbosa P, Mariante Rocha A, Franco da Cruz Lima A, Heleno de Oliveira B, Benigna Martinelli de Oliveira M, Gunilla Skare Carnieri E, Cadena SM and Eliane Merlin Rocha M: Hispidulin: Antioxidant properties and effect on mitochondrial energy metabolism. Free Radic Res 39: 1305-1315, 2005.

15. Chulasiri M, Bunyapraphatsara $\mathrm{N}$ and Moongkarndi P: Mutagenicity and antimutagenicity of hispidulin and hortensin, the flavonoids from Millingtonia hortensis L. Environ Mol Mutagen 20: 307-312, 1992.

16. Clavin M, Gorzalczany S, Macho A, Muñoz E, Ferraro G, Acevedo $\mathrm{C}$ and Martino V: Anti-inflammatory activity of flavonoids from Eupatorium arnottianum. J Ethnopharmacol 112: 585-589, 2007.

17. Gao H, Xie J, Peng J, Han Y, Jiang Q, Han M and Wang C: Hispidulin inhibits proliferation and enhances chemosensitivity of gallbladder cancer cells by targeting HIF-1 $\alpha$. Exp Cell Res 332: 236-246, 2015.

18. Walesiuk A, Nazaruk J and Braszko JJ: Pro-cognitive effects of Cirsium rivulare extracts in rats. J Ethnopharmacol 129: 261-266, 2010.

19. Niu X, Chen J, Wang P, Zhou H, Li S and Zhang M: The effects of hispidulin on bupivacaine-induced neurotoxicity: Role of AMPK signaling pathway. Cell Biochem Biophys 70: 241-249, 2014.

20. Zhou R, Wang Z and Ma C: Hispidulin exerts anti-osteoporotic activity in ovariectomized mice via activating AMPK signaling pathway. Cell Biochem Biophys 69: 311-317, 2014. 
21. Yang L, Yu Z, Qu H and Li M: Comparative effects of hispidulin, genistein, and icariin with estrogen on bone tissue in ovariectomized rats. Cell Biochem Biophys 70: 485-490, 2014.

22. Lee J: 3,3'-Diindolylmethane inhibits TNF- $\alpha$ - and TGF- $\beta$-induced epithelial-mesenchymal transition in breast cancer cells. Nutr Cancer 71: 992-1006, 2019.

23. Livak KJ and Schmittgen TD: Analysis of relative gene expression data using real-time quantitative PCR and the $2-\Delta \Delta C T$ method. Methods 25: 402-408, 2001.

24. Massagué $\mathrm{J}$ and Chen YG: Controlling TGF-beta signaling. Genes Dev 14: 627-644, 2000

25. Gorsch SM, Memoli VA, Stukel TA, Gold LI and Arrick BA: Immunohistochemical staining for transforming growth factor beta 1 associates with disease progression in human breast cancer. Cancer Res 52: 6949-6952, 1992.

26. Mani SA, Guo W, Liao MJ, Eaton EN, Ayyanan A, Zhou AY, Brooks M, Reinhard F, Zhang CC, Shipitsin M, et al: The epithelial-mesenchymal transition generates cells with properties of stem cells. Cell 133: 704-715, 2008

27. Fuxe J, Vincent $T$ and Garcia de Herreros A: Transcriptional crosstalk between TGF- $\beta$ and stem cell pathways in tumor cell invasion: Role of EMT promoting Smad complexes. Cell Cycle 9: 2363-2374, 2010

28. Lee KW, Bode AM and Dong Z: Molecular targets of phytochemicals for cancer prevention. Nat Rev Cancer 11: 211-218, 2011.

29. Lv L, Zhang W, Li T, Jiang L, Lu X and Lin J: Hispidulin exhibits potent anticancer activity in vitro and in vivo through activating ER stress in non-small-cell lung cancer cells. Oncol Rep 43 1995-2003, 2020.

30. Woo SM, Seo SU, Kim SH, Nam JO, Kim S, Park JW, Min KJ and Kwon TK: Hispidulin enhances TRAIL-mediated apoptosis via CaMKK $\beta / A M P K / U S P 51$ axis-mediated bim stabilization. Cancers (Basel) 11: 1960, 2019.

31. Jang HJ, Lee SJ, Kim CY, Hwang JT, Choi JH, Park JH, Lee SW and Rho MC: Effect of sunlight radiation on the growth and chemical constituents of Salvia plebeia R.Br. Molecules 22: 1279, 2017.

32. Gao $\mathrm{H}$, Wang $\mathrm{H}$ and Peng $\mathrm{J}$ : Hispidulin induces apoptosis through mitochondrial dysfunction and inhibition of P13k/Akt signalling pathway in HepG2 cancer cells. Cell Biochem Biophys 69: 27-34, 2014.

33. Han M, Gao H, Xie J, Yuan YP, Yuan Q, Gao MQ, Liu KL, Chen XH, Han YT and Han ZW: Hispidulin induces ER stress-mediated apoptosis in human hepatocellular carcinoma cells in vitro and in vivo by activating AMPK signaling pathway. Acta Pharmacol Sin 40: 666-676, 2019.

34. Holliday DL and Speirs V: Choosing the right cell line for breast cancer research. Breast Cancer Res 13: 215, 2011.

35. Lou Y, Preobrazhenska O, auf dem Keller U, Sutcliffe M, Barclay L, McDonald PC, Roskelley C, Overall CM and Dedhar S: Epithelial-mesenchymal transition (EMT) is not sufficient for spontaneous murine breast cancer metastasis. Dev Dyn 237: 2755-2768, 2008.

36. Wu Y and Zhou BP: New insights of epithelial-mesenchymal transition in cancer metastasis. Acta Biochim Biophys Sin (Shanghai) 40: 643-650, 2008

37. Chambers AF, Groom AC and MacDonald IC: Dissemination and growth of cancer cells in metastatic sites. Nat Rev Cancer 2: 563-572, 2002

38. Heerboth S, Housman G, Leary M, Longacre M, Byler S, Lapinska K, Willbanks A and Sarkar S: EMT and tumor metastasis. Clin Transl Med 4: 6, 2015.

39. Ricciardi GR, Adamo B, Ieni A, Licata L, Cardia R, Ferraro G, Franchina T, Tuccari $\mathrm{G}$ and Adamo V: Correction: androgen receptor (AR), E-cadherin, and $\mathrm{Ki}-67$ as emerging targets and novel prognostic markers in triple-negative breast cancer (TNBC) patients. PLoS One 10: e0132647, 2015. Erratum for: PLoS One 10: e0128368, 2015.

40. Nishimura $\mathrm{N}$ and Sasaki T: Cell-surface biotinylation to study endocytosis and recycling of occludin. Methods Mol Biol 440: 89-96, 2008

41. Martin TA, Jordan N, Davies EL and Jiang WG: Metastasis to Bone in human cancer is associated with loss of occludin expression. Anticancer Res 36: 1287-1293, 2016.

42. Eriksson JE, Dechat T, Grin B, Helfand B, Mendez M, Pallari HM and Goldman RD: Introducing intermediate filaments: From discovery to disease. J Clin Invest 119: 1763-1771, 2009.

43. Peuhu E, Virtakoivu R, Mai A, Wärri A and Ivaska J: Epithelial vimentin plays a functional role in mammary gland development. Development 144: 4103-4113, 2017.
44. Ungefroren H: TGF- $\beta$ Signaling in cancer: control by negative regulators and crosstalk with proinflammatory and fibrogenic pathways. Cancers (Basel) 11: 384, 2019.

45. Walker RA and Dearing SJ: Transforming growth factor beta 1 in ductal carcinoma in situ and invasive carcinomas of the breast. Eur J Cancer 28: 641-644, 1992.

46. Grau AM, Wen W, Ramroopsingh DS, Gao YT, Zi J, Cai Q, Shu XO and Zheng W: Circulating transforming growth factor-beta-1 and breast cancer prognosis: Results from the Shanghai Breast Cancer Study. Breast Cancer Res Treat 112: 335-341, 2008.

47. Parvani JG, Taylor MA and Schiemann WP: Noncanonical TGF- $\beta$ signaling during mammary tumorigenesis. J Mammary Gland Biol Neoplasia 16: 127-146, 2011.

48. Xu J, Lamouille S and Derynck R: TGF-beta-induced epithelial to mesenchymal transition. Cell Res 19: 156-172, 2009.

49. Oft M, Peli J, Rudaz C, Schwarz H, Beug H and Reichmann E: TGF-betal and $\mathrm{Ha}$-Ras collaborate in modulating the phenotypic plasticity and invasiveness of epithelial tumor cells. Genes Dev 10: 2462-2477, 1996.

50. Okada H, Ban S, Nagao S, Takahashi H, Suzuki H and Neilson EG: Progressive renal fibrosis in murine polycystic kidney disease: An immunohistochemical observation. Kidney Int 58: 587-597, 2000

51. Oldfield MD, Bach LA, Forbes JM, Nikolic-Paterson D, McRobert A, Thallas V, Atkins RC, Osicka T, Jerums G and Cooper ME: Advanced glycation end products cause epithelial-myofibroblast transdifferentiation via the receptor for advanced glycation end products (RAGE). J Clin Invest 108 $1853-1863,2001$

52. Oloumi A, McPhee T and Dedhar S: Regulation of E-cadherin expression and beta-catenin/Tcf transcriptional activity by the integrin-linked kinase. Biochim Biophys Acta 1691: 1-15, 2004.

53. Colak S and Ten Dijke P: Targeting TGF- $\beta$ Signaling in Cancer. Trends Cancer 3: 56-71, 2017.

54. Kennecke H, Yerushalmi R, Woods R, Cheang MC, Voduc D, Speers CH, Nielsen TO and Gelmon K: Metastatic behavior of breast cancer subtypes. J Clin Oncol 28: 3271-3277, 2010.

55. Shibue T and Weinberg RA: EMT, CSCs, and drug resistance: The mechanistic link and clinical implications. Nat Rev Clin Oncol 14: 611-629, 2017.

56. Al-Hajj M, Becker MW, Wicha M, Weissman I and Clarke MF: Therapeutic implications of cancer stem cells. Curr Opin Genet Dev 14: 43-47, 2004

57. Ashaq A, Maqbool MF, Maryam A, Khan M, Shakir HA, Irfan M, Qazi JI, Li Y and Ma T: Hispidulin: A novel natural compound with therapeutic potential against human cancers. Phytother Res (In press).

58. Liu K, Zhao F, Yan J, Xia Z, Jiang D and Ma P: Hispidulin: A promising flavonoid with diverse anti-cancer properties. Life Sci 259: 118395, 2020. in press.

59. Scoparo CT, Valdameri G, Worfel PR, Guterres FA, Martinez GR, Winnischofer SM, Di Pietro A and Rocha ME: Dual properties of hispidulin: Antiproliferative effects on HepG2 cancer cells and selective inhibition of ABCG2 transport activity. Mol Cell Biochem 409: 123-133, 2015.

60. Gao H, Jiang Q, Han Y, Peng J and Wang C: Hispidulin potentiates the antitumor effect of sunitinib against human renal cell carcinoma in laboratory models. Cell Biochem Biophys 71: 757-764, 2015.

61. Wang Y, Liu W, He X and Fei Z: Hispidulin enhances the anti-tumor effects of temozolomide in glioblastoma by activating AMPK. Cell Biochem Biophys 71: 701-706, 2015.

62. Yang JM, Hung CM, Fu CN, Lee JC, Huang CH, Yang MH, Lin CL, Kao JY and Way TD: Hispidulin sensitizes human ovarian cancer cells to TRAIL-induced apoptosis by AMPK activation leading to Mcl-1 block in translation. J Agric Food Chem 58: 10020-10026, 2010.

63. Cong Y, Wu S, Han J, Chen J, Liu H, Sun Q, Wu Y and Fang Y: Pharmacokinetics of homoplantaginin in rats following intravenous, peritoneal injection and oral administration. J Pharm Biomed Anal 129: 405-409, 2016.

This work is licensed under a Creative Commons Attribution-NonCommercial-NoDerivatives 4.0 International (CC BY-NC-ND 4.0) License. 